\title{
Linder Hipotezi: “Türkiye’nin Dış Ticareti için Ampirik Bir Analiz"
}

\author{
Linder Hypothesis: "An Empirical Analysis on Turkey's Foreign Trade"
}

Fatih SAYGILI', Gökçe MANAVGAT²

\begin{abstract}
ÖZET
Linder hipotezi, uluslararası ticaretin büyük ölçüde kişi başına gelir düzeyleri yakın, benzer talep yapılarına sahip olan ülkeler arasında gerçekleştiğini ileri sürmektedir. Bu nedenle, bu alanda yapılan ampirik çalışmalarda Linder değişkeni, dış ticaret yapan ülkelerin kişi başına düşen gelirleri arasındaki farkla temsil edilmektedir. Bu gelir farkı azaldıkça ülkelerin ticaret yoğunluğunun artması Linder hipotezini desteklemektedir

Bu çalışmada, 1995-2012 döneminde Türkiye'nin önemli ticari partneri olan 30 ülkeyle karşılıklı ticaretinde Linder hipotezinin geçerliliği sınanmıştır. Ayrıca, kişi başına gelir düzeylerine göre bu ülkelerin sınıflandırılması, Dünya Bankası'nın sınıflandırması dikkate alınarak yapılmış ve sadece Türkiye'yle aynı gelir grubunda (Üst Orta Gelirli Ülkeler-16 ülke) yer alan ülkelerle dış ticaretinde Linder Hipotezi tekrar test edilmiştir. Türkiye ve dış ticaret ortağı ülkeler arasındaki ticaretinin test edilmesinde "Toplam Linder Talep Etkisini" gösteren çekim modeli (gravity type model) ve panel veri analizi kullanılmıştır. Her iki analizin sonuçları Linder değişkeninin Türkiye'nin ithalat yoğunluğu üzerinde belirgin bir etkisi olduğunu ortaya koyarken, ihracat yönüyle hipotezi desteklememektedir
\end{abstract}

Anahtar kelimeler: Linder hipotezi, Türkiye dış ticareti, çekim modeli, panel veri analizi.

\section{GíRiş}

1970'li yıllara kadar uluslararası ticareti açıklamada etkin bir teori olarak görülen Hecksher-Ohlin-Samuelson (H-O-S) "Faktör Donatımı Teorisi", ülkelerin göreli olarak bol sahip oldukları üretim faktörünü (emek-sermaye) yoğun olarak gerektiren malların üretiminde uzmanlaşıp, bu malların ihracatçısı olacaklarını öngörmektedir. Başka bir ifadeyle, dış ticareti belirleyen etkenin ülkelerin faktör donatımı ve malların faktör yoğunluğu olduğuna vurgu yapan, dış ticaretin zengin ülke ve göreli fakir ülke arasında gerçekleşeceğini ifade eden arz yönlü bir yaklaşımdır.

Leontief (1953)'in uluslararası ticaret akımlarının böyle bir yapı içinde gerçekleşmediği yönünde sonuç veren çalışması (Leontief Paradoksu), H-O-S modelinin yeniden sorgulanmasına ve alternatif yeni teori

\begin{abstract}
The Linder hypothesis implies that international trade occurs between countries that have similar level of per capita income with similar demand structure. Therefore, in empirical studies the absolute value of per capita income differences of the countries is defined as Linder (explanatory) variable. Linder hypothesis is supported if trade intensity increases as per capita income differences of the countries decrease.

In this paper, the empirical validity of the Linder hypothesis is tested for Turkey's bilateral trade with its 30 major trading partners using panel data analysis for the period 1995-2011. Furthermore, this analysis is elaborated by using the gravity type panel data model to test Linder effect on Turkey's bilateral trade only with countries of the similar income level (based on the classification of the World Bank: Upper middle income- 16 countries) for the same period. The results of both tests show a significant effect of Linder variable on Turkey's import intensity, but do not support the hypothesis on the export side.
\end{abstract}

Keywords: Linder hypothesis, Turkey's foreign trade, gravity model, panel data analysis.

ve hipotezlerin geliştirilmesine neden olmuştur. Bu teorilerden biri de dış ticareti talep yönlü yaklaşımla açıklayan Tercihlerde Benzerlik Teorisi (Linder Hipotezi) olmuştur.

İsveçli iktisatçı Staffan Burenstam Linder (1961) ülkelerin ticaret modellerini açıklarken, sanayi mallarının ticaretinde üretim maliyetlerinden çok, zevk ve tercihlerin belirleyici olduğunu ve bu nedenle uluslararası ticaretin, benzer talep yapıları olan ülkeler arasında gerçekleştiğini savunmuştur. Tüketici zevk ve tercihleri ise, ülkelerin gelir düzeyi ile ilişkilidir ve kişi başına gelir düzeyleri birbirine yakın ülkeler benzer malları talep etmektedirler. Bu nedenlerle Linder Hipotezi, "Tercihlerde Benzerlik" ya da "Taleplerin Çakışması" (overlapping-demand) teorisi olarak da adlandırılmaktadır. 
Linder, sanayi malları üretiminin ve çeşitliliğinin öncelikle iç talep koşulları tarafından belirlendiğini, üretim ölçeği genişledikçe artan getirilerin söz konusu olduğunu, son aşamada ise bu ürünlerin benzer zevk ve tercihlere sahip ülkelere ihraç edildiğini belirtmiştir. Bu durum ise ancak kişi başına düşen gelir düzeyi yakın ülkeler arasında gerçekleşebilmektedir (Bernasconi, 2009: 5). Azınlığın talep ettiği mallar ise, yine benzer ülkelerden yapılan ithalat ile karşılanmaktadır. Bu teori, dış ticarette ülkelerin faktör donanımlarını karşılaştırmalı üstünlükler kaynağı olarak gören $\mathrm{H}-\mathrm{O}-\mathrm{S}$ teorisinden ve diğer arz yönlü yeni ticaret teorilerinden farklı olarak, uluslararası ticarete talep yönlü bir açıklama getirmektedir.

Linder Hipotezi uygulamada daha çok gelişmiş ülkeler için test edilmiştir. Gelişmekte olan ülkelerin ihraç mallarının ilksel ve tarımsal mallardan oluşması, ihracatlarında sanayi mallarının oranının düşük olması nedeniyle uygulamada analizlere dahil edilmemişlerdir. Ancak, birçok gelişmekte olan ülkelerin ihracatlarında da imalat sanayi mallarının oranının artması ve ithalatlarının da büyük ölçüde sanayi mallarından oluşması nedeniyle bu ülkeler için de Linder Hipotezi test edilmeye başlanmıştır. Türkiye için yapılan çalışmalar çok sınırlı olduğundan, çalışmamızın literatüre katkı sağlayacağı inancındayız.

Bu çalışmada Türkiye'nin dış ticareti yapısı için Linder hipotezinin geçerliliği test edilmektedir. Çaış̧mayı oluşturan 1995-2012 dönemi için Türkiye ile yoğun ticarette bulunan 30 ülke ve gelir sınıflamasına göre Türkiye'yle aynı gelir grubunda yer alan ülkeler (16 ülke) arasında gerçekleşen ticaretin, gelir farkından ne kadar etkilendiğini, başka bir ifadeyle Linder değişkeniyle ne kadar açıklanabildiğini ortaya koymaya çalışmaktadır. Bu nedenle, ampirik uygulamada "Toplam Linder Talep" etkisini gösteren bir çekim modelinden (Hallak,2006) yararlanılmaktadır. Ayrıca Linder etkisi, hem ithalat hem de ihracat yönlü test edilmektedir.

Çalışma altı bölümden oluşmaktadır. Giriş bölümünü takip eden ikinci bölümde, bu hipotezin ampirik sınanması yönünde yapılan çalışmaları kapsayan literatür yer almaktadır. Üçüncü bölümde ele alınan ülkeler ve Türkiye arasında gerçekleşen karşııklı ticaretin rakamlarla genel bir değerlendirilmesi yapılmaktadır. Dördüncü ve beşinci bölümde ampirik analizimizde kullandığımız model, yöntem ve veriler tanıtılmakta ve bulgular yorumlanmaktadır. Altıncı bölümde ise sonuç ve değerlendirme yer almaktadır.

\section{LITERATÜR}

Dış ticarette tercihlerin benzerliğinin sınanması yönünde ilk çalışma İsveçli iktisatçı Staffan Burenstam
Linder (1961) tarafından gerçekleştirilmiş ve ülkelerin benzer gelir düzeyine sahip olmaları durumunda daha yoğun ticaret yaptıkları sonucuna ulaşmıştır. Linder'in dış ticareti açıklamadaki bu yeni yaklaşımı, daha sonra çeşitli ampirik çalışmaların gerçekleştirilmesine neden olmuştur. Aşağıda bu yönde gerçekleştirilmiş çalışmalar ve elde edilen sonuçlar yer almaktadır.

Linder hipotezine destek verici sonuçlara ulaşan ilk araştırmalardan biri Sailors vd.(1973) tarafından gerçekleştirilmiştir. Sailors vd.(1973) çalışmalarında ticaret ortağı ülkelerin kişi başına düşen gelirlerinin mutlak farkını alarak Linder değişkeni tanımlamışlardır. Korelasyon analizi kullandıkları çalışmalarında, 31 ülke içinde, kişi başına düşen gelirleri benzer olan ülkelerin daha yoğun ticaret yaptıkları sonucuna ulaşmışlardır. Ancak, Sailors vd.(1973) modellerinde ticaret yoğunluğunun coğrafi yakınlıktan etkilenebileceğini dikkate almadıkları ve kontrol değişkeni olarak mesafe değişkenine analizlerinde yer vermedikleri için eleştirilmişlerdir (McPherson vd.,2001).

Kennedy ve McHugh (1980), gelir farklılıkların ticaret eğilimi üzerindeki etkisini, 14 sanayileşmiş ülke için 1960-1975 yılları arasında değerlendirmişlerdir. Dönemler arası (intertemporal) etkileşimi kullanarak mesafe etkisinin göz önünde olduğu bir model kullanmışlardır. Benzer gelir grubundaki ülkelerin aynı coğrafyada kümelenme eğiliminde olduğunu ve bu durumda gelir etkisini ayrıştırmanın daha zor olduğunu belirtmişlerdir. Yaptıkları çalışmanın sonucunda ise, dış ticareti açıklayan yapının Linder etkisi taşımadığını belirtmişlerdir.

Jerry Thursby ve Marie Thursby (1987), dış ticarettin hem arz hem de talep yapısına ilişkin çekim modelini kullanmışlardır. Kesit verisi regresyon analizi uyguladıkları çalışmalarında 17 sanayileşmiş ülke için 1974-1982 dönemleri arasındaki mamul malı ticaretinin çoğu ülke dış ticaretinde Linder hipotezini desteklediği sonucuna ulaşmışlardır. Kanada, Japonya, $A B D$ ve Güney Afrika ülkelerinin yer aldığı çalışmada sadece Kanada ve Güney Afrika için bu hipotezi destekleyen sonuçlar elde etmişlerdir.

Francois ve Kaplan (1996) ise, çalışmalarında iki yönlü ticarette, tercihleri gelir dağılımı etkisiyle de açıklamışlardır. Benzer olmayan (non -homotetik) tercihler ve gelir arttıkça farklı mamul mallara yapıIan harcamaların artacağı varsayımı altında, gelir dağılımı farklıklarının toplam ticareti etkileyebileceğini göstermişlerdir. Başka bir ifadeyle, toplam harcama kalıpları ve ticaret akımları sadece gelir düzeyi ile değil, aynı zamanda dağılımıyla da ilişkilendirilmişler ve çalışmada 36 ülke için Linder etkisinin oluştuğunu saptamışlardır.' 
Chow, Kellman ve Shachmurove (1999) Linder hipotezini Hong Kong, Singapur, Güney Kore ve Tayvan için 1965-1990 dönemi aralığında test etmiştir. Bu ülkelerin en büyük ticaret ortakları OECD ile yaptıkları dış ticaretlerinin, kişi başına düşen gelir düzeyi ve farklılaştırılmış ürün ticareti açısından Linder modeliyle açıklanabileceği sonucuna ulaşmışlardır.

McPherson vd. (2001), daha ileri regresyon tekniklerinin kullanılmasıyla, son yıllarda birçok çalışmanın Linder hipotezini desteklediğini belirtmiştir. Bu çalışmalardan biri olan ve hipotezi gelişmekte olan ülkeler açısından test eden kendi çalışmalarında (McPherson vd.) 6 Doğu Afrika ülkesini (Kenya, Rwanda, Etiyopya Uganda, Sudan ve Tanzanya) incelerken sabit etkiler (fixed-effect) Tobit modeli kullanmışlar ve Tanzanya hariç hipotezin desteklendiğini ortaya koymuşlardır.

Choi (2002), çalışmasında Linder hipotezini, 63 ülke için panel veri seti ile sabit etkiler (fixed-effect) yöntemini kullanarak, değiştirilmiş çekim modeliyle (modified gravity-type) test etmiştir. 1970, 1980, 1990 ve 1992 yılları için gerçekleştirdiği çalışmasında Linder hipotezinin desteklendiğini, ayrıca 1990' larda hipotezin daha da güçlendiğini belirtmiştir.

Fillat-Castejon ve Serrano-sanz (2004), İspanya üzerine gerçekleştirdikleri çalışmalarında, 1959-1986 dönemi verilerini kullanarak benzer tercihleri, ulusal gelir dağılımı, kişi başına gelir düzeyi ve coğrafi yakınsama gibi unsurlarla değerlendirmişlerdir. Özellikle ülkeler arası benzer olmayan tercihlerde dış ticaret yapısı için önemli etkenin coğrafi yakınlık olduğuna, benzer talep yapıları için ise, dış ticareti belirleyen en önemli unsurun iç talep olduğuna ve dış piyasaya sunulan malların iç talebin bir uzantısı olacağı sonucuna varmışlardır.

Hallak (2006) çalışmasında, Linder hipotezini "Toplam Linder Talebi" adını verdiği çekim modelini kullanarak test etmiş ancak, gelir farkının yakınsaması durumunda ticaret eğiliminin artması yönünde olumlu sonuçlara ulaşamamıştır. Aynı zamanda çalışmasında, dış ticarette ürün kalitesinin etkisini ayrıntılı incelemiştir. Kişi başına daha yüksek gelir elde eden ülkelerin daha kaliteli mal grupları talep ettikleri, dış ticarette de bu tür malları ithal ettiklerini belirtmiştir. Bu çalışmanın en önemli savı ise, Linder Hipotezinin ancak sektörel verilerle oluşturulan bir modelde destek bulacağıdır, nitekim 64 ülke için 1995 verileriyle yaptığı çalışmada Linder hipotezini destekleyen sonuçlar elde etmiş̧tir.

Atik (2006), Türkiye ve Türkiye'nin komşu olduğu diğer üç ülke için (Yunanistan, İran ve Suriye) Linder hipotezini, panel veri analizi sabit etkiler yöntemiyle test etmiş̧ir. Analize dahil edilen ülkelerin ithalat değerlerinin bağımlı değişken olarak kabul edildiği modelinde, dört ülkenin dış ticaretinde de Linder teorisinin geçerli olduğunu ortaya koymuştur.

\section{TÜRKIYE'NIN GELIR GRUPLARINA GÖRE, ÜLKELERLE OLAN KARŞILIKLI TICARETI}

Çalışmanın bu bölümünde, Türkiye'nin en fazla dış ticarette bulunduğu ülkeler gelir grupları (Dünya Bankası'nın gelir sınıflaması) itibariyle dikkate alınmıştır. Tablo 1' de Türkiye'nin aynı ve üst gelir grubundaki ülkelerle yapmış olduğu ihracat ve ithalatın toplam içindeki payları iki dönem (1995-2004 ve 2005-2012) olarak verilmiştir. Bu rakamların ortalama on yıllık dönemler itibariyle verilmesinin nedeni, Türkiye'nin gelir gruplarına göre ülkelerle olan ihracat ve ithalatındaki değişimi daha net ortaya koyabilmektir.

Türkiye'nin gelir gruplarına göre dönemler arası yapmış olduğu dış ticaret yapısını 30 önemli ticaret ortağı için incelediğimizde (Tablo 1), her iki dönemde (1995-2004 ve 2005-2012) de hem ihracat hem de ithalatın toplam içindeki payları açısından, üst gelir grubu ülkeleriyle yapılan dış ticaretin, Türkiye ile aynı gelir grubunda yer alan ülkelere göre daha fazla olduğu görülmektedir. Ancak, üst gelir grubu ülkelerle yapmış olduğu karşılıklı ticareti bu dönemler itibariyle göreli azalma eğilimi içindeyken, benzer gelir grubu ülkelerle artış eğilimi göstermektedir.

1995-2004 döneminde, Türkiye'nin aynı gelir grubunda yer aldığı ülkelere yapmış olduğu ihracatının, toplam ihracatı içindeki payı \%12.88 iken, 2005-2012 döneminde $\% 50$ oranında artış göstererek toplam ihracatının \%19.37'ne ulaşmıştır. Fakat üst gelir grubu ülkeleriyle yapılan ihracatta ise aynı dönemler arasında $\% 20$ oranında bir azalma görülmektedir. 
Tablo 1: 1995-2012 Dönemleri Arasında Türkiye'nin Gelir Gruplarına Göre Ülkelerle Yaptığı Ticarettin Payları ( \%)

\begin{tabular}{|c|c|c|c|c|c|c|c|c|c|}
\hline & \multicolumn{2}{|c|}{ İhracat \% } & \multicolumn{2}{|c|}{ İthalat \% } & & \multicolumn{2}{|c|}{ İhracat \% } & \multicolumn{2}{|c|}{ İthalat \% } \\
\hline $\begin{array}{l}\text { Orta Düzeyde } \\
\text { Yüksek Gelirli } \\
\text { Ülkeler }\end{array}$ & $\begin{array}{l}1995- \\
2004\end{array}$ & $\begin{array}{l}2005- \\
2012\end{array}$ & $\begin{array}{l}1995- \\
2004\end{array}$ & $\begin{array}{l}2005- \\
2012\end{array}$ & $\begin{array}{l}\text { Yüksek Gelirli } \\
\text { Ülkeler }\end{array}$ & $\begin{array}{l}1995- \\
2004\end{array}$ & $\begin{array}{l}2005- \\
2012\end{array}$ & $\begin{array}{l}1995- \\
2004\end{array}$ & $\begin{array}{r}2005- \\
2012\end{array}$ \\
\hline Rusya & 3.84 & 4.98 & 6.88 & 12.37 & Almanya & 17.83 & 10.25 & 14.39 & 10.03 \\
\hline Romanya & 1.54 & 2.43 & 1.21 & 1.70 & A.B.D & 8.48 & 3.95 & 7.04 & 5.91 \\
\hline Cezayir & 1.34 & 1.25 & 1.37 & 0.56 & İngiltere & 7.22 & 6.60 & 5.09 & 2.87 \\
\hline Çin & 1.06 & 2.66 & 2.71 & 8.26 & İtalya & 6.60 & 6.02 & 8.24 & 5.79 \\
\hline İran & 1.05 & 2.66 & 1.82 & 4.15 & Hollanda & 3.20 & 2.47 & 2.70 & 1.67 \\
\hline Bulgaristan & 1.03 & 1.46 & 0.92 & 1.03 & İspanya & 2.91 & 3.25 & 2.81 & 2.65 \\
\hline Azerbaycan & 0.80 & 1.28 & 0.13 & 0.51 & Fransa & 5.53 & 5.13 & 6.26 & 4.50 \\
\hline Libya & 0.55 & 1.02 & 0.77 & 0.17 & Suudi Arab. & 1.58 & 1.78 & 1.46 & 0.65 \\
\hline Kazakistan & 0.50 & 0.73 & 0.43 & 0.78 & Yunanistan & 1.54 & 1.49 & 0.67 & 0.90 \\
\hline Türkmenistan & 0.35 & 0.72 & 0.18 & 0.18 & Birleşik ArpE. & 1.30 & 3.66 & 0.12 & 0.59 \\
\hline Makedonya & 0.30 & 0.22 & 0.05 & 0.03 & Avusturya & 1.06 & 0.76 & 1.11 & 0.78 \\
\hline Malezya & 0.28 & 0.11 & 0.58 & 0.66 & Polonya & 0.98 & 1.26 & 0.45 & 0.91 \\
\hline Sirbistan & 0.27 & 0.31 & 0.07 & 0.07 & Japonya & 0.45 & 0.24 & 3.27 & 2.00 \\
\hline Tayland & 0.18 & 0.10 & 0.37 & 0.66 & Güney Kore & 0.24 & 0.25 & 2.10 & 2.52 \\
\hline Brezilya & 0.15 & 0.41 & 0.61 & 0.74 & Toplam \% & 58.91 & 47.11 & 55.73 & 41.76 \\
\hline Bosna- Hersek & 0.12 & 0.25 & 0.01 & 0.03 & & & & & \\
\hline Toplam \% & 12.88 & 19.37 & 18.12 & 31.88 & & & & & \\
\hline
\end{tabular}

(Kaynak: Türkiye Cumhuriyeti Ekonomi Bakanlığı, Dış Ticaret İstatistikleri (2013). Kendi hesaplamalarımız.)

İthalat açısında değerlendirildiğinde ise, 19952004 döneminde, Türkiye'nin aynı gelir grubu ülkelerinden yaptığı ithalattın toplam ithalattaki payı, \%18.12 düzeyinde gerçekleşmiştir. 2005-2012 döneminde ise bir önceki on yıllık döneme göre \%75 oranında bir artış yaşanmış ve Türkiye'nin toplam ithalatındaki payı \%31.88 olmuştur. 2005-2012 döneminde Türkiye'nin üst gelir grubu ülkelerden gerçekleştirmiş olduğu ithalatında, 1995-2004 dönemine göre yaklaşık \%25 oranında bir azalma yaşanmıştır. Türkiye'nin üst gelir grubu ülkelerinden yapmış olduğu ithalatındaki azalma, yine bu gelir grubu ülkelerine yaptığı ihracatındaki azalmadan daha yüksek orandadır. Her ne kadar üst gelir grubunda yer alan ülkelerle ticaret yoğunluğumuz halen oransal olarak daha fazla ise de, Türkiye'nin dış ticaret yapısında önemli bir değişim göze çarpmaktadır.

Linder Hipotezi açısından Türkiye ve yoğun ticaret ilişkileri içinde bulunduğu ülkeleri, gelir gruplarına göre değerlendirdiğimizde (Tablo 1), son dönemlerde aynı gelir grubunda yer aldığımız ülkelerle yapılan ihracat ve ithalatımızda $\% 50$ ve daha fazla oranda artış görülmektedir. On yıllık dönemler itibariyle ortaya ko- nulmuş bu tablo bulgularından hareketle gerçekleştirdiğimiz çalışmamızda, bu değişimin Linder hipotezi ile açıklanıp açıklanamayacağını test edilmiştir. Öncelikle 30 ülke analize dahil edilmiş ve gelir farkının azalması durumunda ticaret yoğunluğunu artması yönündeki Linder etkisi sınanmıştır. Daha sonra aynı analiz sadece Türkiye'nin benzer gelir grubunda yer aldığı ülkelerle (16 ülke) yapılmış ve bu ülkelerle olan dış ticaretindeki artışın Linder hipotezi ile açıklanıp açıklanamayacağı da ayrıca test edilmiştir. Takip eden bölümde, bu bölümde yer alan değerlendirmeden yola çıkarak ampirik analizimize ilişkin model ve yöntemi hakkında bilgi verilmektedir.

\section{MODEL VE VERI SETi}

Linder değişkeni, dış ticaret yapan ülkelerin kişi başına düşen gelirleri arasındaki farkla temsil edilmektedir. Bu gelir farkı azaldıkça ülkelerin ticaret yoğunluğunu artması Linder hipotezini desteklemektedir. Bu hipotezin sınamasında, dış ticaret literatüründe sıkça çekim modelinin de kullanıldığı görülmektedir. Çekim modelini (gravity type model) ikili ticaret için kullanan ilk çalışma Jan Timbergen (1962) tarafından 
yapılmıştır. Model zaman içinde farklı değişkenlerle yeniden oluşturulsa da en temel şekliyle; iki ülke arasındaki toplam ticaret hacmi, ülkelerin büyüklükleri (kişi başına düşen milli gelir ya da gayrisafi mili hasıla) ile doğru, mesafe ile ters orantılı olacağını ifade etmektedir. Aşağıda logaritmik dönüşümü yapılmış çekim modeli yer almaktadır.

$\log \left(\right.$ Ticaret $\left._{i j}\right)=\beta_{0}+\beta_{1} \log \left(G D P_{j}\right)+\beta_{2} \log \left(G D P_{j}\right)+\beta_{3} \log \left(\right.$ Mesafe $\left._{i j}\right)$ (1)

Burada $\log \left(\right.$ Ticaret $\left._{\mathrm{ij}}\right)$ iki ülke arasındaki yani i ülkesinden $\mathrm{j}$ ülkesine yapılan ticaret akımlarını göstermekte, $\log \left(G D P_{i}\right)$ ve log(GDP $)$ sırasıyla i, j ülkelerinin milli gelirlerini ve log(Mesafe $\left.{ }_{i j}\right)$ ise, ülkeler arası fiziki uzaklığı ifade etmektedir.

Ayrıca bu modelde, ülkelerin ikili ticaretlerini daha teorik temellere dayandırabilmek için ana değişkenin yanı sıra farklı kontrol değişkenleri de (ticaret politikaları, sınır komşuluğu, ortak dil, nüfus, din gibi diğer faktörler) kullanılmaktadır.

Bu çalışmada Linder hipotezinin ampirik olarak test edilmesinde kullanılan model, Hallak'ın (2006) çalışmasında "Toplam Linder Talep Fonksiyonu" olarak adlandırdığı, farklı kontrol değişkenlerini içeren çekim modelidir. Panel veri yönteminin uygulandığı bu modelde, Türkiye'nin yoğun olarak dış ticarette bulunduğu 30 ülkeyle gerçekleştirdiği dış ticareti bu hipotez kapsamında incelenmiş, Türkiye ile aynı gelir grubunda yer aldığı ülkeler (16 ülke) arasındaki dış ticaret yapısı aynı hipotez kapsamında ayrıca test edilmiştir. 30 ülkeli analizimizden, kendi gelir grubunda bulunduğumuz 16 ülkeyi ayırarak tekrar test etmemizin nedeni ticaret yapımızın ve yönümüzün bu ülkelere doğru gösterdiği olumlu değişimdir. Buna göre tahmin edilen alternatif modellere ilişkin değişkenler aşağıda yer almaktadır (Hallak,2006).

- $\log \left(\mid m p_{i j t}\right)=a+\beta_{1} \log \left(G N P_{i t}\right)+\beta_{2} \log \left(G N P_{j t}\right)+\beta_{3}{ }^{*} \operatorname{Linder}_{i j}+\beta_{4}$ $\log \left(\right.$ Dist $\left._{i}\right)+\beta_{5}$ Dumborder $+\varepsilon_{\text {it }}$

- $\log \left(\operatorname{Exp}_{i j \mathrm{j}}\right)=a+\beta_{1} \log \left(G N P_{i t}\right)+\beta_{2} \log \left(G N P_{j l}\right)+\beta_{3}{ }^{*} \operatorname{Linder}_{i j}+\beta_{4}$ $\log \left(\right.$ Dist $\left._{i j}\right)+\beta_{5}$ Dumborder $+\varepsilon_{i t}$

${ }^{*}$ Linder $_{\mathrm{ij}}=\log \left(\mathrm{PGNP}_{\mathrm{it}}-\mathrm{PGNP}_{\mathrm{jt}}\right)$

Eşitlik 2 ve 3 'de oluşturulmuş çekim modellerinin Linder hipotezine açıklama getirebilecek değişken, yukarıda değinilen genel çekim modeline eklenmiş olan Linder ${ }_{i j}$ değiş̧kenidir. Denklemde Linder ${ }_{i j}, \mathrm{i}$ (Türkiye) ülkesi ve ticaret ortağı j ülkesi arasındaki kişi başına düşen gelir farkının $\left(P\right.$ NNP $_{\text {it }}-$ PGNP $_{\mathrm{jt}}$ ) mutlak değeri şeklinde ifade edilmektedir. Bu değişken cari fiyatlarla satın alma gücüne dayalı olup ABD doları cinsinden hesaplanmıştır. Linder hipotezi iki ülke arasındaki gelir farkının daha az olması durumunda bu ülkelerin daha yoğun ticaret yaptıklarını öngörmektedir. Bu değişkenin hipotezi destekleyen duruma ilişkin işare- ti ise, negatif olmadır. Modelde bağımlı değişkenler ithalat $\left(I m p_{i j}\right)$ ve ihracat $\left(\operatorname{Exp}_{\mathrm{ij}}\right)$ olarak belirlenmiştir. Çünkü Türkiye'nin ticaret ortağı ülkelere yaptığı ticarettin karşılıklı etkisini yansıtabilmek için hem ihracat hem de ithalat yönüyle bir değerlendirme yapmak daha uygun görülmüştür. İthalat $\left(\mathrm{Imp}_{\mathrm{ijt}}\right)$ değeri, t zamanında Türkiye'nin (i) ticaret ortağından (j) yapmış olduğu ithalatı göstermektedir. Hem ihracat hem de ithalat bağımlı değişkenleri cari fiyatlarla ABD doları cinsinden hesaplanmıştır. GNP ${ }_{i}$ ve GNP açıklayıcı değişkenleri sırasıyla; i, Türkiye ve j, Türkiye'nin ticaret ortağı ülkelerinin gayrisafi milli hasıla (cari fiyatlarla satın alma gücüne dayalı -ABD doları cinsinden-) değerlerini ifade etmektedir. Modelde Dist ${ }_{i j}$ açıklayıcı değişkeni, i ve j ülkeleri arasındaki fiziki uzaklığı (başkentler arasındaki uzaklık-km-) ifade etmektedir. Ayrıca kukla değişkeni olarak, Türkiye ile sınır komşuluğu olması durumunda bir, aksi durumda ise sıfır değeri alan sınır kukla değişkeni (Dumborder) kullanılmıştır.

Çalışmada Türkiye'nin ikili dış ticaretinin 19952012 yılları için, kişi başına düşen milli gelir verileri ve gayrisafi milli hasıla değerleri Dünya Bankasının "World Development Indicator" (WDI) veri tabanından sağlanmıştır. İthalat ve ihracat değişkenleri için kullanılan veriler Türkiye Cumhuriyeti Ekonomi Bakanlığı Dış Ticaret İstatistiklerin'den (2013) elde edilmiş ve ülkelerin fiziki uzaklıklarını ifade eden mesafe değişkeni için ise http://www.timeanddate.com/ worldclock/distances, internet sitesinden yararlanılmıştır.

\section{TAHMIN YÖNTEMI VE BULGULAR}

Çalışmada kullanılan değişkenlere ilişkin modelin tahmini için panel veri yöntemi kullanılmıştır. Panel veri setinde hem yatay kesit hem de zaman olmak üzere iki boyut mevcuttur. Başka bir ifadeyle, panel veri modellerinde $\mathrm{N}$ tane birim ve her birime karşı gelen $\mathrm{T}$ adet gözlem bulunmaktadır. Kesit serisinin zaman serisiyle birleştirilmesi daha fazla bilginin kullanılması, değişkenler arasında çoklu doğrusallığın daha az olmasına, serbestlik derecesinin yüksek ve etkin olmasına olanak vermektedir (Gujarati, 2012: 593).

$$
Y_{i t}=X_{i t}^{\prime} \beta+Z_{i} a+\varepsilon_{i t} .(i=1, \ldots, N), \quad(t=1, \ldots, T)
$$

Yukarıdaki bölümde belirttiğimiz iki farklı bağımlı değişken (ihracat ve ithalat açısından) alarak yaptığımı analizde, 1995-2012 yılları için kesintisiz olarak oluşturulmuş dengeli panel veri setinde 18 yıllık ( $T=18)$ bir zaman serisi ve en fazla ticaret yaptığı 30 ülkeyi ele alan $(\mathrm{N}=30)$ kesit serisi yer almaktadır. Ayrıca, aynı zaman serisinde sadece Türkiye ile aynı gelir grubunda yer alan 16 ülkeyi $(\mathrm{N}=16)$ içeren bir kesit serisi kullanılarak bu test tekrarlanmıştır. Bu durumda analizde kullanılan modeller arasındaki fark, hem 
bağımlı değişkenlerden hem de kesit serideki ülke sayısındaki farklılıktan kaynaklanmaktadır.

Panel veri analizi, sabit terim (intercept), eğim katsayıları (slope coefficients) ve hata terimi hakkında yapılan varsayımlara bağlı olarak; sabit katsayılı, sabit etkiler ya da rassal etikler şekillerde tahmin edilmektedir (Green,2003). Sabit katsayılı model, kesit ve zaman serilerini bir araya getirildiğinde, regresyon katsayılarının bütün kesitler için aynı olduğunu, yani hem sabit hem de eğim katsayılarının birimlere ya da zamana göre homojen olduklarını varsaymaktadır. Ancak bu homojenliği kabul etmek ve hata terimini açıklayıcı değişkenle ilişkili olmadığını varsaymak, tahmin katsayılarının tutarsız ve sapmalı olmasına neden olabilir. Gözlenmeyen etkiye ve açıklayıcı değişkenlerle hata terimi arasındaki ilişkinin varlığına bağlı olarak yapılan varsayımlara göre, panel veri analizi sabit ya da rassal etkiler modelleri şeklinde tahmin edilebilir.

Sabit etkiler modelinde (FEM), gözlenemeyen bireysel etkilerin modelde yer alan açıklayıcı değişkenlerle ilişkili olduğu kabul edilir. Sabit etkiler modelindeki her bir bireye ya da kesite özgü gözlemlenmeyen etki, her bir kesite ilişkin bir kukla değişken vererek birimler arası gözlemlenmeyen etkileri hesaba katar. Ancak bu durum, yatay kesitteki N' nin fazla olduğu durumda çok sayıda kukla değişkenin kullanılmasına sebep olması nedeniyle, serbestlik derecesinin düşmesine ve çoklu doğrusal bağıntı problemine de neden olabilmektedir (Green,2003).

Bireysel etkiler eğer modelde yer alan açıklayıcı değişkenlerle ilgili değilse, böyle bir korelasyon yoksa ve örneklemin çok daha büyük ana kütleden çekildiği varsayıldığında rassal etkiler modeli (REM) kullanılmaktadır. Rassal etkilerde, birimler ve/veya zamana bağlı olarak meydana gelen değişmeler, modelde hata teriminin bir bileşeni olarak yer almakta ve genelleştirilmiş en küçük kareler kullanılmaktadır (Green,2003, Gujarati, 2012).

$$
Y_{i t}=a_{i}+\beta_{1 i} x_{1 i t}+\beta_{2 i} x_{2 i t}+\ldots \ldots \ldots \beta_{k i} X_{k i t}+w_{i t}
$$

Model hata terimi $\left(w_{\mathrm{it}}\right)$, birimlerde meydana gelen gözlenemeyen tesadüfi farkları içeren hata teriminden $\left(u_{i}\right)$ ve geri kalan hatalardan $\left(\varepsilon_{i t}\right)$ oluşmaktadır.

Panel veri analizinde çeşitli varsayım ve test istatistiklerinden yola çıkarak uygun model hakkında karar vermek gerekmektedir. Belirleyici olan ilk etken, kesite özgü hata bileşeni ve açıklayıcı değişkenler arasındaki ilişkinin varlığına bağlı olmaktadır. Tablo 2'de analizde kullanılan modele uygun panel veri modeli seçimi için yapılan test sonuçları yer almaktadır.

Tablo 2: Uygun Panel Veri Regresyon Analizi İçin Uygulanan Test İstatistikleri Değerleri

\begin{tabular}{|c|c|c|c|c|c|}
\hline \multicolumn{3}{|c|}{ a.Dış Ticaret Ortağı 30 Ülke İçin } & \multicolumn{3}{|c|}{ b. Aynı Gelir Grubu 16 Ülke İçin } \\
\hline \multicolumn{3}{|c|}{ Model Bağımlı Değişkeni log $\left(\operatorname{Exp}_{\mathrm{ijt}}\right)$} & \multicolumn{3}{|c|}{ Model Bağımlı Değişkeni log $\left(\operatorname{Exp}_{\mathrm{ijt}}\right)$} \\
\hline \multirow{2}{*}{$\begin{array}{l}\text { Hausman Test } \\
\text { (Birimler Arasi-Cross } \\
\text { Sections) }\end{array}$} & $\chi_{2}$ Test İstatistiği & Olasılık Değeri & \multirow{2}{*}{$\begin{array}{l}\text { Hausman Test } \\
\text { (Birimler Arası-Cross } \\
\text { Sections) }\end{array}$} & $\begin{array}{c}\chi_{2} \text { Test } \\
\text { İstatistiği }\end{array}$ & Olasılık Değeri \\
\hline & 0.0000 & 1.0000 & & 0.0000 & 1.0000 \\
\hline $\mathrm{F}_{\text {test cross-section }}$ & 10.6109 & 0.000 & $\mathrm{~F}_{\text {test cross-section }}$ & 10.6178 & 0.000 \\
\hline \multirow{2}{*}{$\begin{array}{l}\text { Breusgh- Pagan Testi LM } \\
\sim \chi^{2}\end{array}$} & LM $_{\text {TEST }}$ & ${ }^{*} \chi_{2}(0.05)$ & \multirow{2}{*}{$\begin{array}{l}\text { Breusgh- Pagan Testi } \\
\text { LM } \sim \chi^{2}\end{array}$} & LM $M_{\text {TEST }}$ & ${ }^{*} \chi_{2}(0.10)$ \\
\hline & 8.8054 & 3.8416 & & 2.9987 & 2.700 \\
\hline \multicolumn{3}{|c|}{ Model Bağımlı Değişkeni $\log \left(\mathrm{Imp}_{\mathrm{ijt}}\right)$} & \multicolumn{3}{|c|}{ Model Bağımlı Değişkeni log $\left(\mathrm{Imp}_{\mathrm{ijt}}\right)$} \\
\hline \multirow{2}{*}{$\begin{array}{l}\text { Hausman Test } \\
\text { (Birimler Arası-Cross } \\
\text { Sections) }\end{array}$} & $\chi_{2}$ Test İstatistiği & Olasılık Değeri & \multirow{2}{*}{$\begin{array}{l}\text { Hausman Test } \\
\text { (Birimler Arası-Cross } \\
\text { Sections) }\end{array}$} & $\begin{array}{c}\chi_{2} \text { Test } \\
\text { Istatistiği }\end{array}$ & Olasılık Değeri \\
\hline & 6.6172 & 0.1576 & & 0.0000 & 1.0000 \\
\hline $\mathrm{F}_{\text {test cross-section }}$ & 8.7005 & 0.0000 & $\mathrm{~F}_{\text {test cross-section }}$ & 16.8030 & 0.000 \\
\hline \multirow{2}{*}{$\begin{array}{l}\text { Breusgh- Pagan Testi LM } \\
\sim \chi 2\end{array}$} & $\mathrm{LM}_{\text {TEST }}$ & ${ }^{*} \chi_{2}(0.05)$ & \multirow{2}{*}{$\begin{array}{l}\text { Breusgh- Pagan Testi } \\
L M \sim \chi^{2}\end{array}$} & $\mathrm{LM}_{\text {TEST }}$ & ${ }^{*} \chi_{2}(0.05)$ \\
\hline & 16.4431 & 3.8416 & & 6.8413 & 3.8416 \\
\hline
\end{tabular}

( Not: * Breusgh- Pagan Testi LM ${ }^{2}$ sınamasında $\chi^{2} 1$ serbestlik derecesi tablo değerleridir.)

Her iki bağımlı değişkenli (ihracat ve ithalat) modeller için yatay kesit ve zaman boyutunu ihmal eden sabit katsayılı model ve birimler arası (cross-section) sabit etkili model arasındaki seçim için yapılan $\mathrm{F}$ testi sonucu; ele alınan ticaret ortaklı modelde (30 ülke) ve aynı gelir grubu ülkeleri için olan modelde (16 ülke) 
sabit katsayılı (pooled) modelinin geçerli olmadığını göstermektedir. Birimlerde meydana gelen gözlenemeyen tesadüfi farkları içeren hata terimi $\left(u_{i}\right)$ ve açıklayıcı değişkenler arasındaki ilişkinin varlığı hakkında yapılan varsayıma dayalı olarak rassal ya da sabit etkiler modellin geçerliliği için ise Hausman testine başvurulmuştur. Her iki farklı bağımlı değişkenli model ve seçilen 30 ülke ve aynı gelir grubu 16 ülke modelleri için elde edilen test sonucunda, istatistik ve olasılık değerlerine göre boş hipotez $\left(\mathrm{H}_{0}\right.$ : Rassal etkiler geçerlidir. REM ve FEM tahmincileri arasındaki fark 0'a yaklaşır) reddedilmez, hata terimi ile açıklayıcı değişkenler arasında ilişki olmadığını göstermektedir.

Bu durum, her ne kadar rassal etkiler modelinin ele aldığımız tüm modellerde geçerli olduğunu ortaya koysa da farklı araştırmacılar, Hausman testi sınanmasının yanında bazı durumlarda rassal ve sabit etkiler modeli seçimi için de varsayımlarda bulunmuşlardır. Çalışmada ele alınan Türkiye ile aynı gelir (Dünya Bankası Üst Orta Gelirli Ülkeler) grubunda yer alan 16 ülkeli modelde, kesit biriminin sayısı (N), zaman serisi verisinden $(T)$ küçük olduğun durumlarda sabit etkiler modelinin kullanılması, etkinliği nedeniyle tavsiye edilmektedir (Hsiao, 2003; Gujarati, 2012). Ayrıca benzer nitelikte ve homojenlikte olduğuna inanılan ana kütleden rassal çekilmeyen örneklemin varlığında -ki burada modellerden biri olan aynı gelir (Dünya Ban- kası Üst Orta Gelirli Ülkeler) grubunda yer alan ülkeler için bu geçerli olmaktadır- sabit etkiler modeli uygun görülmektedir (Baltagi,2005). Yani bu grup kesit için sabit etkiler modelini dikkate almak daha doğru olmaktadır. Ancak, Türkiye ve yoğun ticaret yaptığı 30 ülke için kesit serisi $(N)$, zaman serisinden $(T)$ fazla olduğundan, ele alınan ticaret ortaklarının benzer nitelikte olmayan, farklı ülke grubunu kapsadığından ve Türkiye'nin tüm ticaret ortağı ülkelerini kapsamadığından dolayı rassal etikler geçerli olmaktadır. Breusgh- Pagan Testi LM (1980) ve Hausman testi sonuçları da rassal etkilerin geçerliliğini göstermektedir (Tablo 2).

Panel regresyon sonuçlarının verilmesinden önce model değişkenlerine ait tanımlayıcı istatistik tablosu (Tablo 3) aşağıda verilmiştir. Türkiye'nin 30 dış ticaret ortağı ülkeyle yapmış olduğu ihracatın 1995-2012 yılları arasındaki ortalama değeri 151 milyar dolar (\$) iken, aynı gelir sınıflamasında yer aldığı 16 ülke için bu değer 71 milyar dolar (\$)dır. Aynı dönem için ithalatın ortalama değerleri ise 30 ülke için 270 milyar dolar (\$), aynı gelir grubu ülkeleri için ise 182 milyar dolar(\$) düzeyindedir. Linder değişkeninin belirlenmesinde ise, yoğun olarak dış ticarette bulunduğu tüm ülkeler (30 ülke) ve Türkiye arasındaki kişi başına gelir farkı 11400 dolar (\$), benzer gelir grubu ülkelerle ise bu fark 2800 dolar (\$)dır.

Tablo 3: Değişkenlere İlişkin Tanımlayıcı İstatistikler

Tablo 3.a: Türkiye ve 30 Dış Ticaret Ortağı Arasındaki Dış Ticaret Modeline Iliş̧kin Tanımlayıcı İstatistikler

\begin{tabular}{|l|c|c|c|c|c|c|}
\hline & $\operatorname{Exp}_{\mathrm{ij}}$ & $\mathrm{Imp}_{\mathrm{ij}}$ & $\mathrm{GNP}_{\mathrm{j}}$ & $\mathrm{GNP}_{\mathrm{i}}$ & ${ }^{*}$ Linder $_{\mathrm{ij}}$ & Dist $_{\mathrm{ij}}$ \\
\hline Ortalama & $1.51 \mathrm{E}+09$ & $2.70 \mathrm{E}+09$ & $1.13 \mathrm{E}+12$ & $4.31 \mathrm{E}+11$ & 11444.40 & 3959.867 \\
\hline Medyan & $4.96 \mathrm{E}+08$ & $9.57 \mathrm{E}+08$ & $2.47 \mathrm{E}+11$ & $3.48 \mathrm{E}+11$ & 5122.318 & 2781.500 \\
\hline Maksimum & $1.40 \mathrm{E}+10$ & $8.58 \mathrm{E}+10$ & $1.57 \mathrm{E}+13$ & $7.89 \mathrm{E}+11$ & 42571.54 & 11244.00 \\
\hline Minimum & 290.5144 & 508.4090 & $1.87 \mathrm{E}+09$ & $1.69 \mathrm{E}+11$ & 1.793738 & 634.0000 \\
\hline Standart Sapma & $2.24 \mathrm{E}+09$ & $5.58 \mathrm{E}+09$ & $2.33 \mathrm{E}+12$ & $2.25 \mathrm{E}+11$ & 11911.92 & 3121.801 \\
\hline Olasılık & 0.000000 & 0.000000 & 0.000000 & 0.000000 & 0.000000 & 0.000000 \\
\hline Gözlem & 540 & 540 & 540 & 540 & 540 & 540 \\
\hline Yatay kesit & 30 & 30 & 30 & 30 & 30 & 30 \\
\hline
\end{tabular}

(Not: *Linder (PGNP,-PGNP,))

Tablo 3.b: Türkiye ve Aynı Gelir Grubunda Yer Aldığı 16 Dış Ticaret Ortağı Arasındaki Dış Ticaret Modeline Illişkin Tanımlayııı İstatistikler

\begin{tabular}{|l|c|c|c|c|c|c|}
\hline & $\operatorname{Exp}_{i j}$ & $\operatorname{Imp}_{i j}$ & $\mathrm{GNP}_{j}$ & $\mathrm{GNP}_{i}$ & ${ }^{*}$ Linder $_{i j}$ & Dist $_{i j}$ \\
\hline Ortalama & $7.12 \mathrm{E}+08$ & $1.82 \mathrm{E}+09$ & $3.64 \mathrm{E}+11$ & $4.31 \mathrm{E}+11$ & 2871.769 & 4042.625 \\
\hline Medyan & $2.69 \mathrm{E}+08$ & $3.95 \mathrm{E}+08$ & $5.71 \mathrm{E}+10$ & $3.48 \mathrm{E}+11$ & 2481.936 & 2374.500 \\
\hline Maksimum & $9.92 \mathrm{E}+09$ & $3.14 \mathrm{E}+10$ & $8.23 \mathrm{E}+12$ & $7.89 \mathrm{E}+11$ & 10200.11 & 11244.00 \\
\hline Minimum & 1068.625 & 646.4016 & $1.87 \mathrm{E}+09$ & $1.69 \mathrm{E}+11$ & 1.793738 & 634.0000 \\
\hline Standart Sapma & $1.15 \mathrm{E}+09$ & $4.50 \mathrm{E}+09$ & $9.46 \mathrm{E}+11$ & $2.25 \mathrm{E}+11$ & 1865.746 & 3576.182 \\
\hline Olasılık & 0.000000 & 0.000000 & 0.000000 & 0.000000 & 0.000000 & 0.000000 \\
\hline Gözlem & 288 & 288 & 288 & 288 & 288 & 288 \\
\hline Yatay kesit & 16 & 16 & 16 & 16 & 16 & 16 \\
\hline
\end{tabular}

(Not: *Linder (PGNP,-PGNP $)$ ) 
Yukarıda, sabit eğim katsayısı ve hata terimi hakkında yapılan varsayımlara bağlı olarak panel veri regresyonunun farklı şekillerde tahminlenmesine yönelik yapılan varsayımlar ve test sonuçları verilmiştir. Toplam Linder Talep Fonksiyonu'nu gösteren çekim modellerinde, yukarıda sözü edilen varsayımlardan ve model belirleme testlerinden hareketle; Türkiye ve yoğun ticaret yaptığı 30 ülke için oluşturulan modelde rassal etkiler üzerinden, aynı gelir grubu ülkelerin yer aldığı 16 ülke için oluşturulan modelde sabit etki- ler üzerinden değerlendirme yapmak uygun olmaktadır. Bu çerçevede ele aldığımız modellerde otokorelasyon sorununun olup olmadığı da araştırılmıştır. Her iki model içinde otokorelasyon ve değişen varyans sorununun giderilmesi için white cross-section düzeltmesi yapılmıştır. Böylece değişen varyans sorununu düzeltmek için sağlam (robust) standart hatalar elde edilmiştir. Bu düzeltmeler yapıldıktan sonra modellere ilişkin tahmin sonuçları Tablo 4' te verilmiştir.

Tablo 4 : Panel Veri Regresyon Sonuçları

\begin{tabular}{|c|c|c|c|c|}
\hline & \multicolumn{2}{|c|}{$\begin{array}{c}\text {-Tüm Ülkeler- } \\
\text { Rassal Etkiler Modeli } \\
\text { Random Effects-Cross-Section- }\end{array}$} & \multicolumn{2}{|c|}{$\begin{array}{l}\text { - Aynı Gelir Grubu Ülkeler - } \\
\text { Sabit Etkiler Modeli } \\
\text { Fixed Effects-Cross-Section- }\end{array}$} \\
\hline & $\begin{array}{c}\text { Bağımlı değişken } \\
\log \left(\operatorname{Exp}_{\mathrm{ijt}}\right)\end{array}$ & $\begin{array}{c}\text { Bağımlı değişsen } \\
\log \left(\operatorname{Imp} p_{i j t}\right)\end{array}$ & $\begin{array}{c}\text { Bağımlı değişken } \\
\log \left(\operatorname{Exp}_{\mathrm{ijt}}\right)\end{array}$ & $\begin{array}{l}\text { Bağımlı değişken } \\
\text { Log }\left(\operatorname{Imp} p_{\mathrm{iji}}\right)\end{array}$ \\
\hline $\log \left(G N P_{j}\right)$ & $\begin{array}{c}0.4907^{* * * *} \\
{[0.0940]}\end{array}$ & $\begin{array}{c}0.7006^{* * * *} \\
{[0.0509]}\end{array}$ & $\begin{array}{l}0.4473^{*} \\
{[0.3238]}\end{array}$ & $\begin{array}{c}0.4759^{* * * *} \\
{[0.1419]}\end{array}$ \\
\hline $\log \left(G N P_{i}\right)$ & $\begin{array}{c}0.9228^{* * *} \\
{[0.1521]}\end{array}$ & $\begin{array}{c}0.6409^{* * * *} \\
{[0.0825]}\end{array}$ & $\begin{array}{c}0.8919^{* * *} \\
{[0.2635]}\end{array}$ & $\begin{array}{c}0.8246^{* * *} \\
{[0.2137]}\end{array}$ \\
\hline Log(Linder) & $\begin{array}{c}0.0282 \\
{[0.0815]}\end{array}$ & $\begin{array}{c}-0.1167^{* *} \\
{[0.0521]}\end{array}$ & $\begin{array}{l}-0.0069 \\
{[0.4507]}\end{array}$ & $\begin{array}{c}-0.1667^{* * *} \\
{[0.0529]}\end{array}$ \\
\hline $\log \left(\right.$ Dist $\left._{i j}\right)$ & $\begin{array}{c}-0.9504^{* * *} \\
{[0.2492]}\end{array}$ & $\begin{array}{l}-0.1763 \\
{[0.1730]}\end{array}$ & $\begin{array}{c}0.0988 \\
{[0.0903]}\end{array}$ & $\begin{array}{l}0.1976^{* *} \\
{[0.0856]}\end{array}$ \\
\hline Dumborder & $\begin{array}{c}0.3392 \\
{[0.1972]}\end{array}$ & $\begin{array}{c}0.6648 \\
{[0.5669]}\end{array}$ & $\begin{array}{c}0.7313 \\
{[0.2925]}\end{array}$ & $\begin{array}{c}1.5596 \\
{[0.1895]}\end{array}$ \\
\hline Sabit Terim & $\begin{array}{l}10.0839 \\
{[3.7667]}\end{array}$ & $\begin{array}{l}14.6948 \\
{[2.4222]}\end{array}$ & $\begin{array}{l}16.3082 \\
{[2.9255]}\end{array}$ & $\begin{array}{l}17.2901 \\
{[2.8586]}\end{array}$ \\
\hline $\mathrm{R}^{2}$ & 0.3308 & 0.3587 & 0.6189 & 0.7775 \\
\hline Adj. $R^{2}$ & 0.3245 & 0.3527 & 0.5904 & 0.7608 \\
\hline F istatistiği & $52.8059^{* * *}$ & $59.7619^{* * *}$ & $21.6873^{* * *}$ & $46.6613^{* * *}$ \\
\hline D-W istatistiği & 1.9866 & 1.9636 & 1.9960 & 1.9878 \\
\hline Gözlem sayısı & 540 & 540 & 288 & 288 \\
\hline Ülke sayısı & 30 & 30 & 16 & 16 \\
\hline $\mathrm{F}_{\text {test cross-section }}$ & - & - & $10.6178(0.000)$ & $16.8030(0.000)$ \\
\hline Hausman test istatistiği & $0.0000(1.0000)$ & $6.6172(0.1576)$ & & \\
\hline Breusch -Pagan LM $\left(X^{2}\right)$ & $8.8054^{* * *}$ & $16.4431^{* * *}$ & & \\
\hline
\end{tabular}

( Not: 1- * \% 10 anlamlılığı; ** \% 5 anlamlığı; *** \% 1 anlamlılığı göstermektedir. Köşeli parantez [] içindeki değerler standard hatalardır. $F_{\text {test }}$ ve Hausman test istatistiği için parantez ( ) olasılık değerini ifade etmektedir. 2- Sabit ve rassal etkiler modelinde yatay kesitte birimler arası etkiyi göstermektedir.)

Türkiye ve analize dahil edilen 30 ticaret ortağı ülke ve Türkiye ile aynı gelir grubunda yer alan 16 ticaret ortağı için oluşturulmuş ihracat ve ithalat bağımlı değişkenli modeller için sonuçlar Tablo 4'te yer almaktadır. Analize dahil edilen tüm ülkeler (30 ülke) açısından ihracat bağımlı değişkeniyle oluşturulan modelde, Linder açıklayıcısının katsayısı negatif işaretli olmamasının yanı sıra, istatistiki olarak da anlamIı sonuç vermemiştir. Yani gelir farkındaki bir azalma Türkiye'nin bu ülkelere yaptığı ihracatında artışa ne- den olabilecek talep etkisi yaratmamaktadır. Ancak bağımlı değişkenin ithalat seçilmesi durumunda geçerli olan rassal etkiler modeli için Linder değişkeni $\% 5$ anlamlılık düzeyindedir ve hipotezi destekleyen beklenti işareti olan negatif değeri almıştır. Türkiye ve ticaret yaptığı ülkeler arasında kişi başına düşen gelir farkı azaldıkça, Türkiye'nin bu ülkelerden yapmış olduğu ithalat artmaktadır. Türkiye ve dış ticarette bulunduğu bu ülkeler arasındaki gelir farkının \%1 azalması, Türkiye'nin yapmış olduğu ithalatını yaklaşık \% 0.11 
artırmaktadır. Açıklayıcı değişkenlerden gayrisafi milli hâsıla (GNP) değeri istatistiki olarak \%1 düzeyinde anlamlıdır ve Türkiye'nin dış ticaret ortaklarının gelirlerindeki \%1'lik artış, Türkiye'nin ithalatını yaklaşık \% 0.70 artmaktadır. Yine GNP değişkeni \%1 düzeyinde anlamlıdır ve Türkiye'nin gelirinde meydana gelen \%1'lik bir artış, Türkiye'nin bu ülkelere yaptığı ithalatını yaklaşık \% 0.64 düzeyinde artırmaktadır. Bu durum Türkiye'nin ithalatındaki artışın kendi ithalatının gelir esnekliğinden çok, karşı ülkenin ihracatının gelir esnekliğinden kaynaklandığını göstermektedir. Bu model için yine dış ticarette ülkeler arası fiziki uzaklığı ifade eden (Dist $t_{\mathrm{ij}}$ ) açıklayıcı değişkeni ve komşuluk kukla değişkeni istatistiki olarak anlamlı sonuçlar vermemektedir. Türkiye'nin ticaret ortağı ülkelerden yaptığı ithalat, mesafe azaldıkça artmamaktadır.

Türkiye ve aynı gelir grubunda yer alan 16 ticaret ortağı ülkeyi kapsayan ithalat ve ihracat bağımlı değişkenli modeller için tahmini katsayılarını değerlendirdiğimizde; ihracat bağımlı değişkenli modelde Linder değişkeni negatif işaret almış olmasına karşın istatistiki olarak anlamlı değildir. Ancak ithalat bağımlı değişkeniyle oluşturulmuş modelde, Linder değişkeni \%1 düzeyinde anlamlıdır. Türkiye ve ticaret ortakları arasındaki kişi başına gelir farkı azaldıkça (\%1'lik bir azalma), Türkiye'nin bu ülke grubundan ithalatını arttırdığı (\%0.16) sonucuna ulaşılmaktadır. Ancak ihracatımız açısından böyle bir durum söz konusu değildir. Ayrıca ithalatçı ülke (GNP) ve Türkiye'nin (GNP)'si açıklayıcı değişkenleri dikkate alındığında, Türkiye ile aynı gelir grubunda yer alan ülkelerin, Türkiye'ye yönelik yaptığı mal ihracatında gelir esnekliği, Türkiye'nin gelir esnekliğinden daha fazla olduğunu göstermektedir. Diğer bir ifadeyle, Türkiye'nin ithalatındaki (karşı ülkenin ihracatındaki) artışta, karşı ülkenin gelir artışının etkisi daha fazladır. Bu durum genel olarak yoğun dış ticarette bulunduğu 30 ülkeyle değerlendirdiğimiz model de ortaya çıkan sonuçla aynıdır. Mesafe (Dist $t_{i i}$ ), açıklayıcı değişkeni bu modelde istatistiki olarak anlamlı ve pozitiftir. Bu durum mesafe azaldıkça Türkiye'nin ithalatını artırıcı etki yaratmadığını göstermektedir.

\section{SONUÇ VE DEĞERLENDIRMELER}

Çalışmamızda, Türkiye ve ticaret ortağı ülkeler arasındaki karşıııklı ticaretin Linder hipotezi açısından geçerliliği sınanmıştır. Türkiye'nin dış ticaret yapısının Linder hipotezine uygunluğu tek yönlü olmaktadır. Başka bir ifadeyle, hem yoğun olarak ticaret yaptığı ortaklar açısından, hem de aynı gelir düzeyinde yer aldığı ülkeler açısından; Türkiye'nin mal ithal etme eğilimi, diğer ülkelerle arasındaki kişi başına düşen gelir farkındaki azalmadan etkilenirken, ihraç etme eğiliminde böyle bir etki (Linder etkisi) görülmemektedir.

Türkiye ve yoğun ticaret yaptığı 30 ülke ve bu ülkeler arasında yer alan ve Türkiye ile aynı gelir düzeyine sahip 16 ülke için yaptığımız analizlerde; gelir farklılığındaki azalmaya bağlı ticaret artış eğilimini açıklayan Linder değişkeni, Türkiye'nin ithalatı açısından (\%1 düzeyinde) anlamlı çıkmıştır. Ticaret ortağı ülkeler ve Türkiye arasındaki gelir farkının azalması (\% 1 'lik azalma) Türkiye'nin bu ülkelerden yapmış olduğu ithalatı yaklaşık \% 0.11 düzeyinde arttırdığını göstermektedir. Aynı gelir grubundaki ülkelerden yaptığı ithalatında ise bu oran yaklaşık \%0.16 düzeyindedir. Fakat model bağımlı değişkenin ihracat olması durumunda, Türkiye'nin tüm ticaret ortakları ve aynı gelir grubunda yer aldığı ülkelerle ihracatında Linder etkisi oluşmamaktadır.

Linder hipotezine göre, talep yapılarının benzerliğine bağlı karşıııklı ticaret daha çok gelişmiş ülkeler arasında olmaktadır. Türkiye'nin yoğun olarak dış ticarette bulunduğu ticari ortakları dikkate alındığında, Türkiye'nin daha çok endüstrileşmiş, üst gelir grubundaki ülkelere ihracat yapması ve ihracatında sanayi malları oranının göreli olarak düşük olması, Linder hipotezinin ihracat yönünde neden desteklenmediğini açıklamaktadır.

Türkiye'nin aynı gelir grubundaki ülkelerle gerçekleştirdiği karşılıklı ticarette dönemler itibariyle artışta Linder etkisi, ihracattaki artışı açıklayamamış, yalnızca ithalattaki artışı açıklamada geçerli olmuştur. Aynı gelir grubu ülkelerinden yapmış olduğu ithalatı dikkate alındığında, gelir farkındaki azalmanın ithalatındaki artışa yansıması ise, Türkiye'nin bu ülkelerle benzer mallar ürettiği ve talep ettiği şeklinde yorumlanabilir. 


\section{SON NOTLAR}

${ }^{1} \mathrm{Bu}$ yönde yapılmış diğer benzer çalışmalar için bakılabilir; Hunter (1991), Fieler, (2007), Dalgin vd. (2008).

${ }^{2}$ Breusch - Pagan LM (1980) Test sınması için uyguladığımız formül,

$$
L M=\frac{\left(\sum_{i=1}^{N} T_{i}\right)^{2}}{2\left(\sum_{i=1}^{N} T_{i}\left(T_{i}-1\right)\right)}\left[\frac{\sum_{i=1}^{N}\left(\sum_{t=1}^{T_{i}} \hat{e}_{i t}\right)^{2}}{\sum_{i=1}^{N} \sum_{t=1}^{T_{i}} \hat{e}_{i t}^{2}}-1\right]^{2} \sim \chi^{2}(1)
$$

\section{KAYNAKLAR}

Atik, H. (2006) “Tercihlerde Benzerlik Teorisi: Türkiye ve Bazı Komşu Ülkelerin Dış Ticareti Üzerine Bir Analiz" Ankara Üniversitesi Sosyal Bilimler Fakültesi Dergisi, 61(2): 34-43

Baltagi, B. H. (2005) Econometric Analysis of Panel Data, 3rd Edition, Southern Gate, Chichester John Wiley \& Sons Ltd.

Bernasconi, C. (2009) "New Evidence For The Linder Hypothesis And The Two Extensive Margins of Trade" http://www.sgvs.ch/congress09/upload/p_283.pdf (Erişim Tarihi, 11.06.2013)

Choi, C. (2002) "Linder Hypothesis Revisited" Applied Economics Letters, 9(9):601-605.

Chow, P., Kellman, M. ve Shachmurove, Y. (1999) "A Test of the Linder Hypothesis in Pacific NIC Trade 19651990" Applied Economics, 31(2):175-182.

Dalgin, M., Trindade, V. ve Mitra, D. (2008) "Inequality, Nonhomothetic Preferences, and Trade: A Gravity Approach" Southern Economic Journal, Southern Economic Association, 74(3):747-774.

Fieler, A. (2007) "Non-Homotheticity and Bilateral Trade: Evidence and a Quantitative Explanation" mimeo NYU.

Fillat-Castejon, C. ve Serrano-Sanz, J.M. (2004) "Linder Revisited: Trade and Development in the Spanish Economy" International Review of Applied Economics, 18(3):323-348.

Francois, J. ve Kaplan, S. (1996) "Aggregate Demand Shifts, Income Distribution, and the Linder Hypothesis" Review of Economics and Statistics, 78(2):244-250.

Gujarati , D.N ve Poter, D.C.(2012) Basic Econometrics, Çev. Şenesen E.,Şenesen G. Literatür Yayınları.

Greene, W.H. (2003) Econometric Analysis, 3rd Edition, Prentice Hall.

Hallak, J.C. (2010) "A Product-Quality View of The Linder Hypothess" The Review of Economics and Statistics, 92(3): 453-466.
Hallak, J.C. (2006) "A Product-Quality View of The Linder Hypothesıs” IPC Working Paper Series, No 24.

Hsiao C. (2003) Analysis of Panel Data, 2rd Edition, Cambridge University Press.

Hunter, L. (1991) "The Contribution of Nonhomothetic Preferences to Trade" Journal of International Economics, 30:345-358

Kennedy, T.E. ve McHugh, R. (1980) "An Intertemporal Test And Rejection Of The Linder Hypothesis" Southern Economic Journal, 46(3):898- 903.

Linder, S. (1961) "An Essay on Trade and Transformation" Uppsala, Almqvist and Wiksells.

McPherson, M.A., Redfearn, M.R. ve Tieslau, M. (2001) "International Trade and Developing Countries: An Empirical Investigation of the Linder Hypothesis" Applied Economics, 33(5):649-57.

Thursby, J. ve Thursby, M. (1987) "Bilateral Trade Flows, the Linder Hypothesis, and Exchange Risk" Review of Economics and Statistics, 69:488-495.

Sailors, J.W. Qureshi, U.A. ve Cross, E.M. (1973) "Empirical Verification Of Linder's Trade Thesis" Southern Economi Journal , 40(2):262-68.

Yılmaz, S.E. (2010) Dış Ticaret Kuramlarının Evrimi, Eflatun Yayın Evi.

Tinbergen, J.(1962) Shaping the World Economy: Suggestions for an International Economic Policy, New York, Twentieth Century Fund

Türkiye Cumhuriyeti Ekonomi Bakanlığı, Dış Ticaret İstatistikleri (2012-2013, Ocak- Nisan Dönemi) http://www.ekonomi.gov.tr/index.cfm?sayfa=7155BE01D8D3-8566-45208351967592CF (10.11.2013)

World Bank (2012) World Development Indicators http://data.worldbank.org/indicator/NY.GDP.MKTP. CD. (10.11.2013) 